\title{
The development of a Human Factors Readiness Level tool for implementing industrial human-robot collaboration
}

\author{
George Charalambous $^{1} \cdot$ Sarah R. Fletcher $^{1} \cdot$ Philip Webb $^{2}$
}

Received: 21 August 2016 / Accepted: 11 December 2016/Published online: 6 January 2017

(C) The Author(s) 2017. This article is published with open access at Springerlink.com

\begin{abstract}
The concept of industrial human-robot collaboration (HRC) is becoming increasingly attractive as a means for enhancing manufacturing productivity and product. However, due to traditional preventive health and safety standards, there have been few operational examples of true HRC, so it has not been possible to explore the organisational human factors that need to be considered by manufacturing organisations to realise the benefits of industrial HRC until recently. Charalambous, Fletcher and Webb (2015) made the first attempt to identify the key organisational human factors for the successful implementation of industrial HRC through an industrial exploratory case study. This work enabled (i) development of a theoretical framework of key organisational human factors relevant to industrial HRC and (ii) identification of these factors as enablers or barriers. Although identifying the key organisational human factors (HF) was an important step, it presented a crucial question: when should practitioners involved in HRC design and implementation consider these
\end{abstract}

George Charalambous

george.ch@hotmail.co.uk

Sarah R. Fletcher

s.fletcher@cranfield.ac.uk

Philip Webb

p.f.webb@cranfield.ac.uk

1 Industrial Psychology and Human Factors Group, Centre for Structures Assembly and Intelligent Automation, School of Aerospace, Transport and Manufacturing, Cranfield University, Bedford MK43 0AL, UK

2 Centre for Structures Assembly and Intelligent Automation, School of Aerospace, Transport and Manufacturing, Cranfield University, Bedford MK43 0AL, UK factors? New industrial processes are typically designed and implemented using a maturity or readiness evaluation system, but these do not incorporate of or link to any formal considerations of HF. The aim of this paper is to expand on the previous findings and link the key human factors in the theoretical framework directly to a recognised industrial maturity readiness level system to develop a new Human Factors Readiness Level (HFRL) tool for system design practitioners to optimise successful implementation of industrial HRC.

Keywords Human factors - Human-robot collaboration . Industrial robots · Technology readiness · Automation acceptance $\cdot$ Intelligent automation

\section{Introduction}

\subsection{Concept of industrial HRC}

Many manufacturing processes can be optimised with the seamless integration of industrial robots and human operators so that the superior attributes of each are best exploited. Humans react very well in response to external influences and variabilities, such as engineering tolerances or process variations while industrial robots have the ability to handle high payloads with greater speed and accuracy, without suffering from fatigue. The human physical dexterity and cognitive reasoning that is still needed for many skilled production tasks cannot yet be replaced by robots, but robots can provide the strength and repeatability needed for many less skilled and unhealthy tasks [1]. Thus combining the advantages of human workers and robots leads to the development of industrial human-robot collaboration (HRC). 


\subsection{Human factors for the implementation of manufacturing technologies}

Close collaboration between humans and industrial robots has traditionally been prevented due to safety concerns. Recent technological advancements [2-4] have led to health and safety standards adopting a more progressive approach which allow, to some extent, closer HRC [5]. However, as the traditional preventive health and safety default position has been to completely segregate robots from people in industry, it is not yet fully understood how human operators will behave in more collaborative environments. The implementation of such a radical manufacturing change can be a challenge not only from a technical and production point of view but also from a human factors perspective. After a long history of enforcing boundaries between robotics and workforces, manufacturing system designers and automation engineers have little understanding of how to incorporate human factors into their design and implementation processes.

Literature from comparable contexts, such as the implementation of advanced manufacturing technologies (AMT) and cellular manufacturing $(\mathrm{CM})$, provides a valuable lesson about how inattention to designing for the human element can be detrimental. For instance, for the introduction of AMT, some reports highlight that nearly $50-75 \%$ of implementations have failed in terms of quality, flexibility, and reliability [6], but the problems do not appear to lie with the machinery or the technologies itself but with the inattention to human related issues [7-10]. Also, numerous studies have suggested that the introduction of new advanced technologies and practices impose significant organisational challenges and require a fundamental transition in the way business is conducted which in turn is affecting the human element [11-13]. Similar observations were made for the implementation of CM. Although the benefits of CM have made it a sought-after strategy, manufacturing firms largely fail to achieve successful implementation and grasp its full benefits $[14,15]$ due to lack of understanding of the human and social related issues $[14,16]$.

The introduction of an industrial HRC system will generate comparable challenges. Merely rolling out industrial robots onto the shop floor will not ensure acceptance and effective use. These intelligent work systems will inevitably alter workers' job roles and organisational protocols. With the concept of industrial HRC still at its infancy, it is therefore crucial to understand the key human factors that need to be considered for the successful implementation of industrial HRC.

\subsection{Previous work on industrial HRC}

To our knowledge, the human factors of industrial HRC have not been sufficiently explored until our own efforts recently and this is likely to be a result of there being little or no example of true industrial HRC in a state of implementation or operation that could have been studied. To address this problem, Charalambous, Fletcher and Webb [17] made the first attempt to identify the key organisational human factors for the successful implementation of industrial HRC by studying previous work in comparable contexts and also by conducting a case study of comparable live industrial automation implementation. The results of this work enabled (i) development of an initial theoretical framework which proposes the key organisational human factors relevant to industrial HRC and (ii) identification of whether these factors are enablers or barriers [18]. A brief summary of these findings is listed below:

(i) Major enablers identified: operator participation in the implementation, communication of the change to the workforce, visible senior management commitment and support to the project, provision of training to the workforce, empowerment of the workforce and existence of a process champion during the implementation.

(ii) Major barriers identified: lack of union involvement, lack of awareness of the manual process complexity by the system integrator, capturing the variability of the manual process prior to introducing the automated system and allocation of resources for the development of the automated system.

\subsection{Purpose of this paper: introducing the Human Factors Readiness Level tool}

Although identifying the key human factors is an important step, a crucial question for practitioners involved in design and integration of the technology that now arises is when to consider these factors in their implementation processes. For instance, our findings identified that it is important to communicate the change to the workforce and involve shop floor operators in the implementation process, but the question remains: 'When should we do that?' To our knowledge, the findings by Charalambous, Fletcher and Webb [17] reflect the only study which has looked at the organisational human factors of industrial HRC. For this reason, the purpose of this paper is to expand on their output and make an attempt to provide practitioners with a Human Factors Readiness Level (HFRL) tool which incorporates these factors to optimise the potential for successful implementation of industrial HRC.

The development and implementation of new technologies and processes typically involve following a framework of manufacturing or technology readiness assessments where maturity and capability are evaluated at key developmental stages or gateways from concept through to full operational deployment. However, these frameworks currently do not include any human factor considerations. To ensure that the key 
human factors are also considered systematically at appropriate stages of process/technology development a technology readiness level (TRL) method will be used.

\section{Technology readiness levels}

The technology readiness level (TRL) is a widely used scale communicating the maturity of a new technology before it can be utilised [19]. There are a number of TRL frameworks that have been adopted by the US Department of Defense [19, 20] and other organisations in safety critical industries [21, 22]. Figure 1 provides an example of a TRL scale used for NASA's purposes along with a definition for each level. It must be noted that the TRL scale and the definitions for each level can vary according to the industry and the unique features of each organisation.

As shown, a TRL scale consists of nine levels, each of which represents a different technology maturity level. As the technology readiness level increases, the technology reaches a higher level of operational readiness. Clearly then, as the TRL increases, the criticality of ensuring the technology is accepted and adopted by the workforce then it becomes a vital element. If, for example, the project reaches a TRL 6 or 7 , but the ground work to prepare the workforce has not been carried out, then acceptance and adoption are likely to be poor. This could potentially translate to a major financial loss for the company in addition to the negativity and scepticism that is likely to plague any future technological implementation attempts. Therefore, it is crucial to integrate the key human factors on the TRL as the project matures.

Fig. 1 NASA's technology readiness levels scale (retrieved from [19])
At this point, it is deemed important to clarify that the TRL scale has been chosen as it is a widely used scale for communicating technology maturity levels [22]. It is acknowledged that other technology maturity assessment scales have been developed over the years [23]. For instance, some manufacturing organisations use the manufacturing capability readiness level (MCRL or MRL) framework to indicate the manufacturing maturity of a technology thus identifying any underlying manufacturing risks [24]. The fundamental underpinning of these frameworks is still the same. To this end, our work describing the integration of human factors on a TRL scale is applicable to other technology maturity evaluation frameworks.

An initial attempt to map the key organisational human factors identified by the work conducted by [17] on a TRL scale is presented in the following section along with descriptions and recommendations for suitable activities to aid the integration. The output of this work represents the development of a new HFRL tool for the successful implementation of industrial HRC.

\section{The development of the Human Factors Readiness Level tool}

\subsection{TRLs 1 and 2}

TRLs 1 and 2 are looking at the basic principles of the technology concept and a description/early demonstration of the applicability and validity of the concept. In the context of industrial HRC, it is important to understand the current manual process and how a HRC scenario can be used to optimise the manual process. Therefore, at this stage, it is critical to

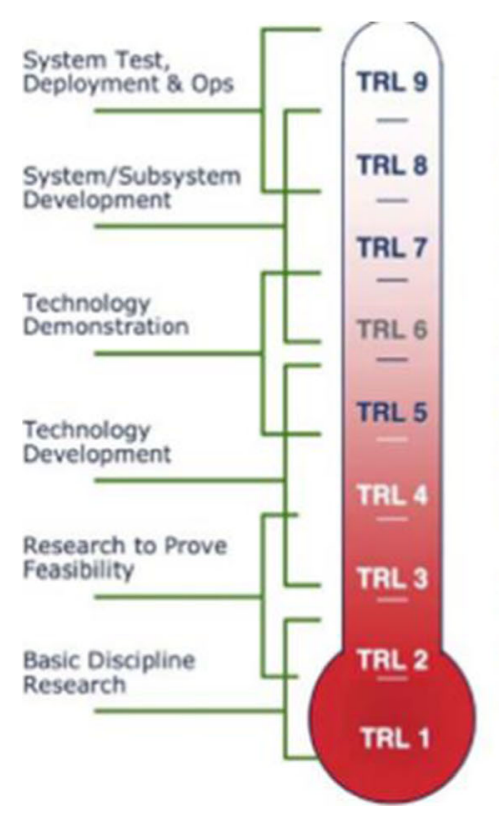

Actual system "proven" through successful system and/or mission operations

Actual system completed and :qualified" through test \& demonstration (in the operational environment

System prototype demonstration in the planned operational environment

System/subsystem model or prototype demonstration in a relevant environment (Ground or Space)

Component and/or breadboard validation in relevant environment

Component and/or breadboard validation in 'laboratory' environment

Analytical and experimental critical function and/or characteristic proof-of-concept

Technology concept and/or application formulated

Basic principles observed and reported 
capture the complexity and variability of the manual process. To do this, it implies that shop floor operators will need to participate. It is recommended that at this stage, the most experienced operators are invited to participate. This is because the more experienced ones have a greater understanding of the overall process and how is completed. These individuals are defined here as 'major users'. The benefits of doing this are twofold:

(i) Experienced operators (i.e. major users) are engaged and feel the organisation values and acknowledge their knowledge. This is likely to make them less reluctant in releasing information about how they complete the task.

(ii) A database is created whereby the manual process variability is recorded. This is a crucial point. It is possible that for some processes, no standard operating procedures (SOPs) exist. In some other occasions, SOPs exist; however, operators adapt the procedures to complete the process. Therefore, by doing a human skill capture of the manual process at an early stage will provide vital information regarding the key process variables and the complexity of the process. The outcome of this process will dictate what parts of the process can be automated and what parts of the processes are better retained as manual.

\section{Summary}

The recommendations suggested above are shown in Fig. 2 . During the initial stages of the development (i.e. TRLs 1 and 2 ), capturing the complexity of the manual process is a vital factor (left hand side of the figure). In order to do that, it is imperative for a selective number of shop floor employees (most experienced) to participate and provide their insight regarding the manual process (right hand side).

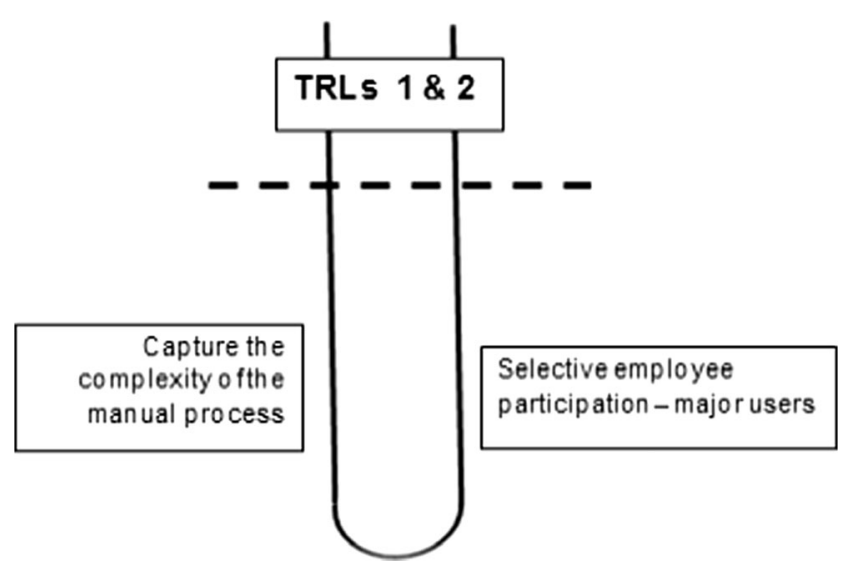

Fig. 2 Organisational human factors at TRLs 1 and 2

\subsection{TRLs 3 and 4}

TRLs 3 and 4 reflect the stage of trial tests using representative equipment at laboratory conditions are taking place. First of all, at this stage the system integrator (SI) will be involved in order to supply the equipment (e.g. industrial robot and any other equipment) and run trials. Therefore, there are two important points to note: (i) SI involvement and (ii) trial execution. To accomplish these, the following suggestions are made:

\subsubsection{System integrator involvement}

The SI will need to have a comprehensive understanding of the process in order to deliver a process capable system. The knowledge gained during the human skill capture (at TRLs 1 and 2) must be passed to the SI. This will enable the SI to understand the complexity of the process. An off-the-shelf industrial robot might not be applicable, particularly if the process to be automated is complicated and requires significant manual input. Therefore, understanding the complexity of the manual process will enable an early discussion between the SI and the development team (the company's team assigned to implement the technology) as to how the system can reach a process capable stage.

\subsubsection{Trial execution}

A selective number of shop floor operators will need to be further engaged at this stage as they will be working closely with the SI to run the trials. First of all, since trials will start taking place, it is important for operators to participate more rigorously. As before, during these trials, it is important to have experienced operators. Therefore, the more experienced individuals (i.e. major users) could be invited to participate and assist the trials which will take place either in house (i.e. within the company's premises) or externally (e.g. SI's premises). The benefits of this approach are the following:

(i) Operators (i.e. 'major users') gain ownership of the system and it becomes their process rather than it just being viewed as a 'management's pet' project.

(ii) Their involvement will provide valuable information to the SI and the development team regarding the usability of the system. For example, operators will be able to indicate if they would prefer certain layouts and provisions such as, for example, a special rack nearby to place tools.

(iii) The major users can act as indirect means of cascading information to the rest of the operators at the working cell. Operators are more likely to be open to information coming from 'one of their own'. Therefore, this will 
reduce scepticism and negativity when the system is eventually installed on the shop floor.

Second, communication avenues with the affected workforce must be initiated. Two major points need to be addressed: (i) who is to do the communication and (ii) what must be communicated.

(i) Who is to do the communication? The communication process can be initiated by the process champion. The process champion is likely to have some knowledge regarding the manual process as well as what is expected in the future process (i.e. in a HRC scenario). This will appear more credible to the employees.

(ii) What must be communicated? As discussed in previous work in Reference [17], effective communication can be used to provide employees with a degree of information as to why, how and when these changes will take place [25]. Therefore, it is important to communicate the rationale for the change. According to Jimmieson, Peach and White [26], communicating the reasons for the change reduces uncertainty while increasing employee personal control over the upcoming change which in turn can generate change-supportive intentions. Shop floor employees need to be aware of why the changes are taking place, when the change is likely to occur and the impact of the change on their work routines. It is understood that in some cases, the development team might not have all the answers, however, it is still important to provide as clear information as possible to avoid rumour spreading which can doom the project before it even starts [27, 28].

Third, at this stage, it is also beneficial to begin communicating the need for the change to the union. In a unionised environment, employees are likely to belong to be members and influenced by union concerns so it is important that they are also aligned. In the example of a HRC implementation scenario, if, as suggested above, shop floor operators are provided with information regarding a new technology and are supporting trials, the union representatives will need to know. Lack of communicating to the union could create friction and possible impediment if the union were to influence members not to support the project. Furthermore, the union, just like the employees, need to be provided with a clear rationale. It is suggested to provide the union with the business case indicating the reasons for the change. Also, it is important to communicate to the union an overall plan highlighting what is the likely impact of this change to the workforce. If, for instance, shop floor employees are to be deployed to other work areas, then this needs to be presented and discussed with the union. Finally, a key aspect is to ensure that the same message is communicated to the shop floor employees and to the union. If contradicting or ambiguous messages are being communicated, then this is likely to have an adverse effect.

\subsubsection{Summary}

The recommendations suggested above are shown in Fig. 3. As the project development progresses (i.e. TRLs 3 and 4), it is equally important to intensify human factors integration:

(i) At this stage, the SI will be involved and it is important to have a clear awareness of the manual process and its complexities in order to supply a process capable system. This is shown on the bottom-left hand side of Fig. 3.

(ii) Also, the most experienced shop floor operators will need to be involved in trial execution. Therefore, the participation is still essential. Furthermore, they can provide valuable information to the SI which can help the development of system. This is shown on the bottomright hand side of Fig. 3.

(iii) At the same time, communication avenues with the affected workforce need to be initiated. The process champion can be used as a means for disseminating vital and quality information. The information provided must answer three basic questions: (i) why does the change take place? (i.e. provide the rationale), (ii) when is it going to happen? (i.e. provide a time frame) and (iii) what is the impact on them? (i.e. are they made redundant, moved to another business unit/manufacturing cell etc.) This is shown on the top-right hand side of Fig. 3.

(iv) Simultaneously, communication avenues with the union bodies need to be initiated. Just like the employees, the information provided to the union must answer the three basic questions: (i) why is the change happening, (ii) when is it going to happen and (iii) what is the impact on its members. This is shown on the top-left hand side of Fig. 3.

(v) A crucial point to note is that the information provided to the union and to the employees must be in harmony and not contradicting as this will have the opposite than the desired effect. This is shown at the bottom of Fig. 3 .

\subsection{TRLs 5 and 6}

TRLs 5 and 6 reflect, in a HRC scenario, the capability of the system to achieve satisfactory production rates using actual components. Also, at this stage, the system is likely to be brought to the production facility (i.e. shop floor) and allow a selective number of production personnel (e.g. major users and manufacturing engineers) to operate it. Therefore, at this level, we must note the following: (i) significant input from 


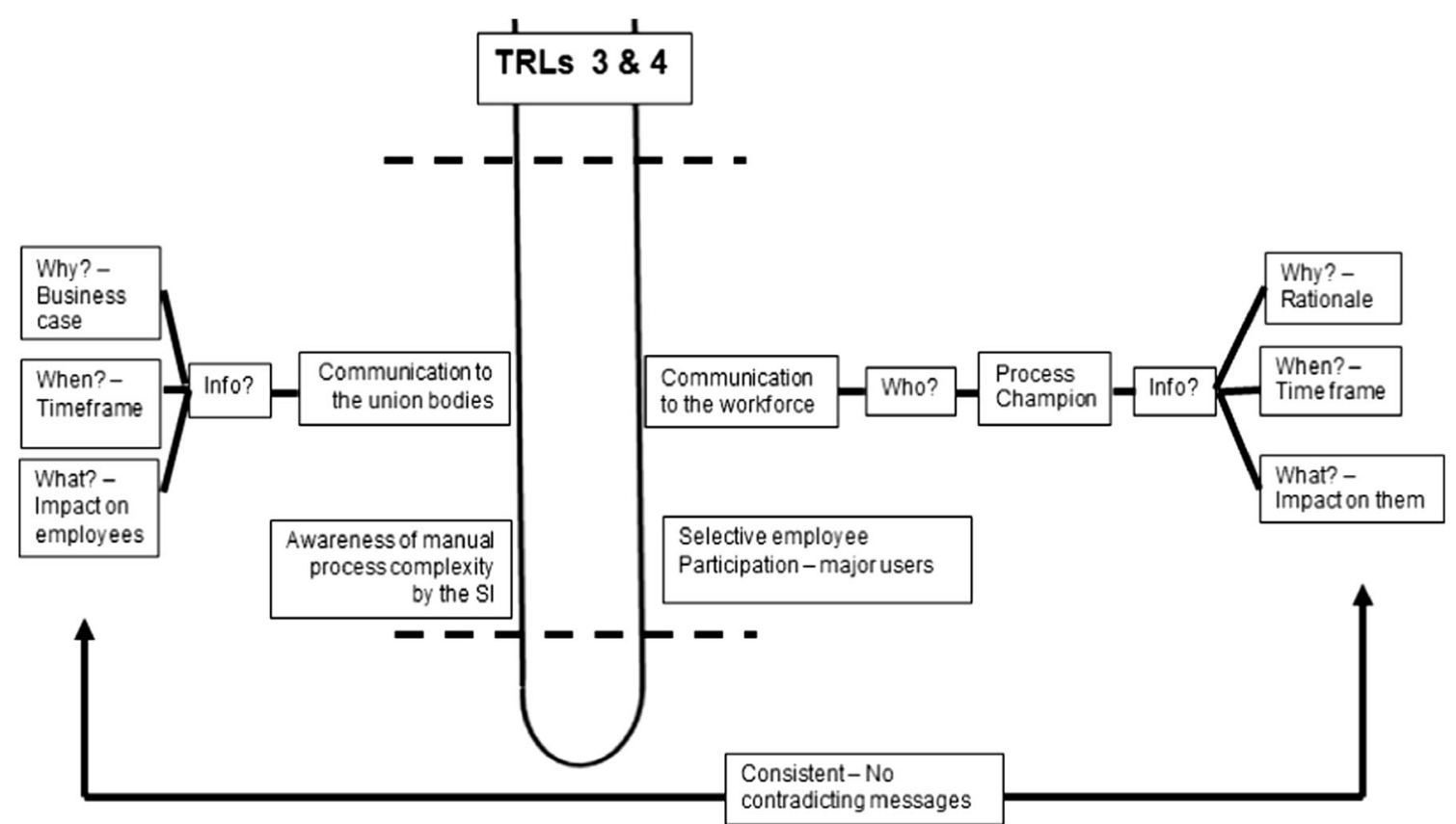

Fig. 3 Organisational human factors at TRLs 3 and 4

production personnel and (ii) increasing use of the system on the shop floor for trials. The following suggestions are made:

\subsubsection{Significant input from production personnel}

First of all, at this level, the operational personnel will need to operate the system using actual components to ensure they are satisfied with the system. It is expected that the major users will be involved in this process as before. As the project is essentially at a pre-production phase, a higher commitment and input from these individuals will be needed. Normally, these individuals would be contributing to the production of their work cell. Therefore, as these individuals are spending more time in developing the system rather on the production, it is possible for the production rates to experience a decline. This could potentially lead to frictions between the production leaders and the project's development team (i.e. the team assigned to implement the new technology). As shown by the exploratory case study undertaken in previous work [17], this could have a negative impact on the operators involved. To reduce negative consequences, it is suggested that the senior management contribute a more visible input. Their input can be shown particularly by allocating the necessary resources (i.e. support from major users and other agents) for the development of the new technology. Evidence from the literature [17] suggested that senior management can be role models and their behaviour and statements can strongly shape employees' beliefs about what is important for the organisation $[29,30]$. Therefore, ensuring the necessary resources are provided for the development of the technology will indicate the importance of the project for the entire organisation. If the allocation of these resources will cause an impact on production rates, these need to be identified and discussed. It is crucial for senior management to have an active role at this stage as the project is entering a critical phase. As literature has highlighted, lack of senior management involvement and support will have adverse effects on the successful implementation of the project [31-33].

Second, at this stage, it is recommended that an operator empowerment plan is initiated. This will indicate the level of operator control over the system during failures, errors and/or deviations. Evidence from the literature [17] highlights that a flexible-oriented strategy (i.e. empowering operators to make decisions) is preferable when complex automated systems are implemented [34, 35]. Operator empowerment will aid operators to gain ownership of the system and understand its operation, rather than passively monitor and call for an expert when the system deviates from normal operations. It is acknowledged that some organisations can be strictly hierarchical where decision-making is given to higher levels, such as manufacturing engineers or production managers. However, for the implementation of industrial HRC, it is vital to dissipate control in the decision-making to the individuals who will be working with the system daily. This will enable greater acceptance. At the same time, it is understood that empowerment will take place in a controlled manner through an official plan where a list of steps are outlined during abnormalities. As suggested in the literature, flexible-oriented and controloriented strategies can be used to complement each other $[36,37]$. Therefore, a reaction plan can provide a structured 


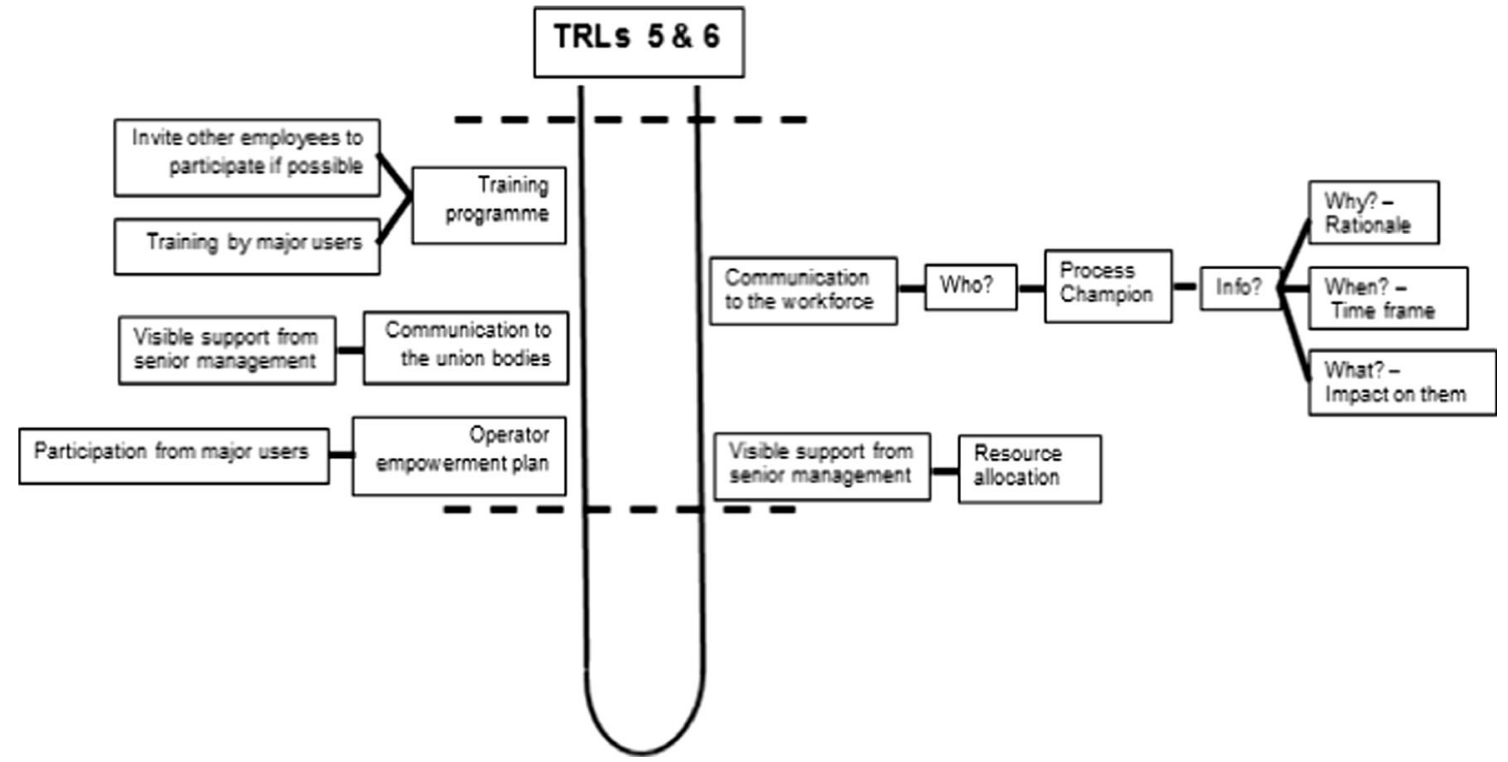

Fig. 4 Organisational human factors at TRLs 5 and 6

approach to abnormal events and can be complemented with enhanced operator control. In addition, the level of control could be discussed with the major users. Their input could be helpful to develop the reaction plan.

\subsubsection{Increasing use of the system on the shop floor for trials}

The increasing trial use of the system will inevitably attract attention from the rest of the shop floor employees, particularly if the factory does not have any previous history with automated systems. At this point, it is vital to continue the communication to employees. As suggested at TRLs 3 and 4, employees need to be informed about why this change is taking place, when it will happen and what the impact will be on their daily jobs. It is vital to continue communicating these messages to ensure employees are aware and prepared, as much as possible, for the upcoming change.

Second, at this stage it is recommended that a training programme be developed for the rest of the workforce operating the system. This will allow employees to engage with the system at an early stage and gain confidence. In addition, the training can be also be used as a means of greater stakeholder engagement and acceptance. This will make the new technology more accessible rather than feeling it is being hidden in fear of resistance, and therefore dissipate anxieties. It is recommended that the major users are employed to deliver
Fig. 5 Organisational human factors at TRLs 7, 8 and 9

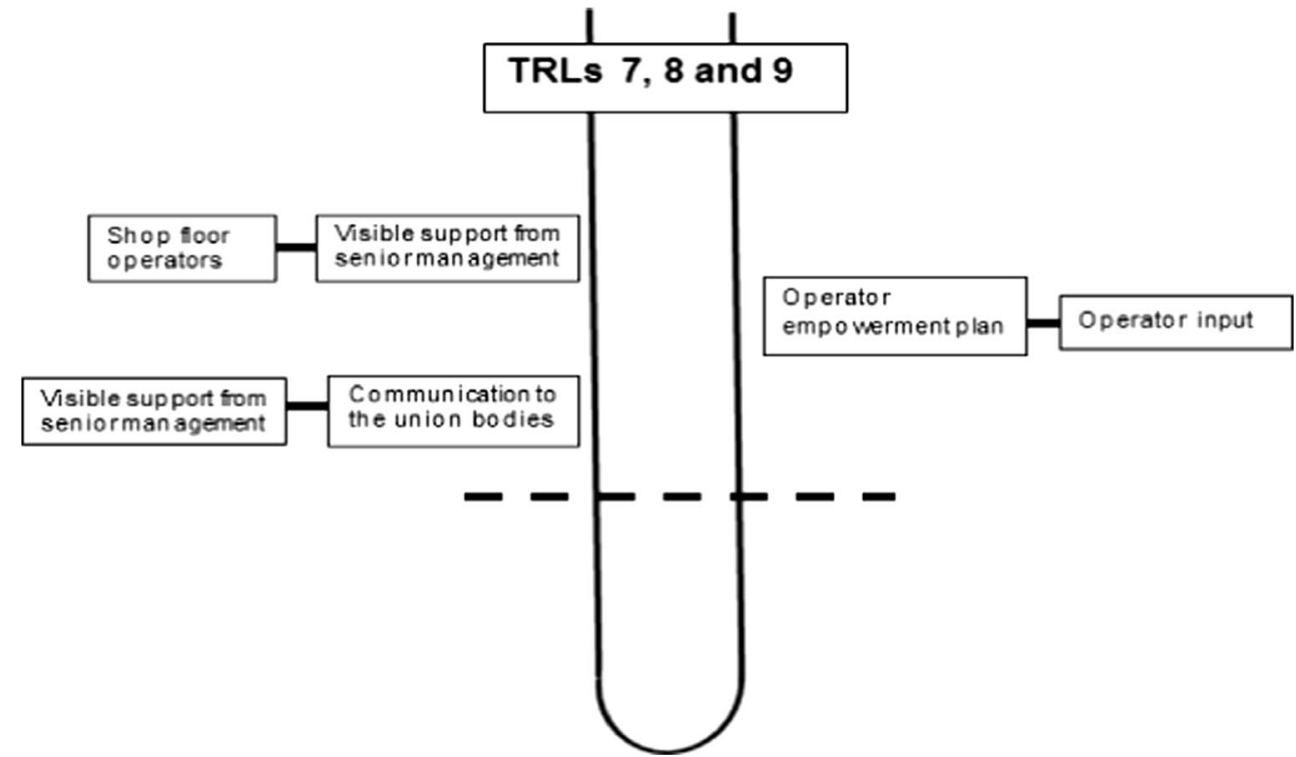




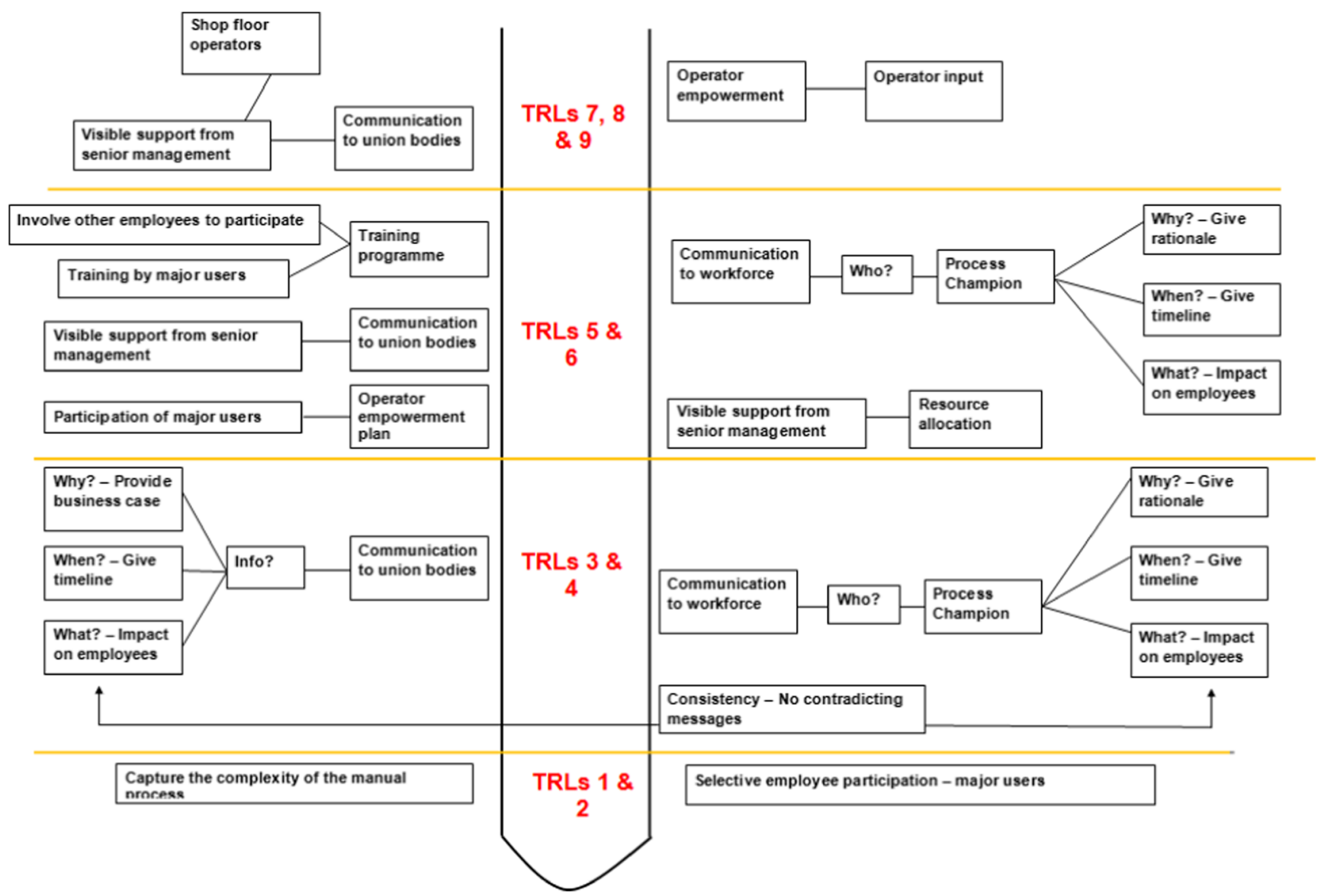

Fig. 6 Schematic for practitioners indicating the key organisational human factors at different TRLs

part of the training. This has two benefits: (i) major users are feeling valued for their input which has a positive impact on their morale and (ii) as discussed before, operators are more likely to accept the system this, if 'one of their own' is giving them the knowledge.

Finally, it is suggested that the union bodies are again involved significantly. This can be via walk-throughs whereby they observe the activities taking place for the development of the system. Also, it is suggested that the senior management are engaged in the communication process with the union. This can assist to show the gravity of the project for the organisation while at the same time, it keeps the union in the loop which in turn enables acceptance of the system.

\subsubsection{Summary}

The recommendations suggested above are shown in Fig. 4. At this stage, the system will be used to prove it can deliver the required production rates (i.e. TRLs 5 and 6). Therefore, as before, intensifying human factors integration is crucial:

(i) At this stage operational personnel will be needed to use the system and enhance its capability prior to entering production. Therefore, allocating the necessary resource for this step is crucial.

(ii) To this end, it is recommended that senior management have a visible input by allocating the resource necessary for this stage. This will send a clear message to all employees regarding the gravity of the project. This is shown on the bottom-right hand side of Fig. 4.

(iii) Next, it is recommended to begin the development of an operator empowerment plan. This will highlight when and to what extend operators have control to intervene and rectify system deviations/failures. This is an important step in order to stress to operators that they will not be 'button-pushers' but will have an active role to fulfil. This is shown on the bottom-left hand side of Fig. 4.

(iv) With the increasing use of the system on the shop floor, communication to the workforce will need to be continued. The same process described earlier (TRLs 3 and 4) is recommended. This is shown on the top-right hand side of Fig. 4.

(v) As before, communication to the union bodies must be continued. At this stage, it is recommended that senior management take a more active role and have regular discussions with the union bodies regarding the new system. This can help mitigate 
Table 1 Key stakeholders at different TRLs and their role

\begin{tabular}{|c|c|c|}
\hline TRL & Stakeholders & Role \\
\hline $\begin{array}{r}\text { TRLs } 1 \\
\text { and } 2\end{array}$ & $\begin{array}{l}\text { Selective number of employees } \\
\text { (i.e. major users) }\end{array}$ & They will be engaged to provide their insight and help capture the complexity of the manual process. \\
\hline \multirow[t]{3}{*}{$\begin{array}{r}\text { TRLs } 3 \\
\text { and } 4\end{array}$} & $\begin{array}{l}\text { Selective number of employees } \\
\quad \text { (i.e. major users) } \\
\text { \& System Integrator (SI) }\end{array}$ & $\begin{array}{l}\text { The SI will need to be made aware regarding the complexity of the manual process in order to supply a } \\
\text { process capable system. Participation of the major users to collaborate with the SI can provide } \\
\text { valuable information. }\end{array}$ \\
\hline & $\begin{array}{l}\text { Remaining workforce } \\
\text { \& Process champion }\end{array}$ & $\begin{array}{l}\text { Communication avenues with the workforce will need to be established to provide information } \\
\text { regarding the new system. Information need to answer three basic questions: (i) why the change is } \\
\text { happening, (ii) when it will happen and (iii) what is the impact on each of them. } \\
\text { The process champion can be used a central point for disseminating the information. }\end{array}$ \\
\hline & Union bodies & $\begin{array}{l}\text { Communication avenues with the union bodies will need to be established to provide information } \\
\text { regarding the new system. Information need to answer three basic questions: (i) why the change is } \\
\text { happening, (ii) when it will happen and (iii) what is the impact to its members. }\end{array}$ \\
\hline \multirow[t]{6}{*}{$\begin{array}{r}\text { TRLs } 5 \\
\text { and } 6\end{array}$} & Senior management & $\begin{array}{l}\text { Allocate the necessary resource for developing the system. This will stress their commitment to the } \\
\text { project and its gravity for the organisation/business unit. }\end{array}$ \\
\hline & & Communication with the union bodies to keep them in the loop. \\
\hline & Union bodies & $\begin{array}{l}\text { More active involvement (e.g. walk-through) to be kept updated regarding the development of the } \\
\text { system. }\end{array}$ \\
\hline & Selective number of employees & Participate in the initial process for the development of an operator empowerment plan. \\
\hline & (15) & Be involved in the provision of training to the remaining of the workforce. \\
\hline & Remaining workforce & $\begin{array}{l}\text { Regular provision of information regarding the new system. } \\
\text { As in TRLs } 3 \text { and } 4 \text {, the process champion can be used a central point for disseminating the information. }\end{array}$ \\
\hline \multirow[t]{4}{*}{$\begin{array}{c}\text { TRLs } 7,8 \\
\text { and } 9\end{array}$} & Senior management & $\begin{array}{l}\text { Provide support to shop floor operators during the early production stages and be updated with any } \\
\text { issues. This will send a clear message that they are committed to supporting the new system and the } \\
\text { employees. }\end{array}$ \\
\hline & & Communication with the union bodies to keep them in the loop. \\
\hline & Union bodies & $\begin{array}{l}\text { Continuation of the communication avenues with the union bodies to ensure they are aware of how the } \\
\text { system development is progressing and are kept in the loop regarding any issues. }\end{array}$ \\
\hline & Workforce & $\begin{array}{l}\text { Wider involvement to establish the operator empowerment plan so that all employees are aware of what } \\
\text { will be expected from them and what actions are to be taken during a system failure/deviation from } \\
\text { normal operating conditions. }\end{array}$ \\
\hline
\end{tabular}

negativity and scepticism regarding the new system and help build mutual trust. This is shown in the middle-left hand side of Fig. 4.

(vi) Finally, a training programme is recommended to be developed at this stage. This will allow the remaining of the workforce to engage with the system and gain more confidence. Also, the training can be delivered by the 'major users'. This is shown on the top-left hand side of Fig. 4.

\subsection{TRLs 7, 8 and 9}

The latter three stages of the TRL reflect the state where the system has proven its capability and the process is qualified for production use. At this final phase, there will be significantly more involvement from the majority of the production personnel. First of all, the operator empowerment plan needs to be established. This approach will assist operators to understand what is expected from them in their new roles. Also, as the system is new, it is more likely to experience adjustment and abnormal events. Therefore, knowledge gained from these events can be updated, in the operator empowerment plan accordingly, making it a live document.

Second, a new manufacturing method is likely to raise uncertainty, so it is important for the senior management to show their support for employees. This can be done with open communication and regular updates from management individuals in an attempt to understand any production issues. At the same time, in a unionised environment, the communication between senior management and the union needs to continue. The union can communicate to the senior management employees' concerns regarding the new manufacturing method.

\subsubsection{Summary}

The recommendations above are shown in Fig. 5. At TRLs 7, 8 and 9 the system will be qualified to enter production. Therefore, the following human factors are suggested: 
(i) The operator empowerment plan should be finalised so that the users are aware of what is expected from them and what steps must be taken if the system deviates. This is shown on the right hand side of Fig. 5.

(ii) Visible senior management commitment and support to the project should continue. It is recommended that open communication avenues are established so that employees are regularly updated regarding any issues. This is shown on the top-left hand side of Fig. 5.

(iii) Similarly, open communication avenues with the union bodies need to be continued to mitigate any friction at this late stages of the project. This is shown on the bottom-left hand side of Fig. 5 .

\subsection{Summary of the Human Factors Readiness Level tool}

The recommendations presented and described above for TRLs 1 to 9 can be placed in an overall schematic which can be used by practitioners involved in HRC design and implementation as a concise tool to inform (i) the key organisational human factors that need to be considered for the implementation of industrial HRC and (ii) when and what kind of action is needed at different TRLs. The overall schematic is shown in Fig. 6.

As it can be seen from the schematic in Fig. 6, as the TRL increases, so does the number of key stakeholders and the importance of integrating human factors to ensure good stakeholder management. A summary of the key stakeholders at different TRLs and their role is provided in Table 1.

\section{Future work}

The HFRL tool presented here is a novel approach to try and link key human factors, identified from empirical and theoretical work, to appropriate gateways in an accepted technology readiness level framework. Future work could be directed towards further development of the HFRL tool based on a wider number of relevant case studies, and also on validation testing of the model using system designers and automation specialists to apply and test the tool. The benefits of real design and implementation practitioners utilising the HFRL tool on real case studies would be twofold.

\subsection{Development of a database}

More frequent use of the HFRL tool will provide more data for modifying/optimising the work presented in this paper and this could be centralised to develop a HFRL database. Then, over time and successive additions of empirical data, the existing HFRL tool will become increasingly valid and accurate.

\subsection{Further development of the Human Factors Readiness Level Tool}

Further use of the HFRL tool would enhance our understanding as to how human factors can be integrated into a TRL scale. As discussed in Section 2, the TRL metric was chosen to map the key organisational human factors as it is a widely used scale [22]; however, it is acknowledged that other technology maturity assessment tools are available [23], and the output of this work would be applicable to these tools (e.g. MRL). A number of advanced manufacturing technology implementation failures have been attributed to a lack of consideration of human factors [35], yet human factors are not yet incorporated into existing manufacturing or technology readiness level scales. Thus, the developed tool is an original and inventive attempt to bridge this gap. This is an important step as automation specialists assigned with the implementation of an industrial HRC cell are expected to use this gated process to introduce such a system. Therefore, further use of this tool would provide a more objective understanding of the key human factors at each TRL. For instance, in some organisations, senior management involvement might be essential at TRL 1; while for others, senior management might be vital at higher TRLs when key decisions are to be made (e.g. TRLs 4 and above). This would make the HFRL tool an attractive solution for automation specialists and project managers as the connection of the HFRL tool with the TRLs gives them the opportunity to be a step ahead and focus simultaneously on the key human factors of each TRL while the system develops on a technical level. In summary, the initiative described would have profound implications, as it would provide a holistic understanding of the human factors for the successful implementation of industrial HRC.

Acknowledgments This research was funded by the EPSRC Centre for Innovative Manufacturing in Intelligent Automation. We give special thanks to the industrial sponsors of the project for assisting with the data collection.

George Charalambous is currently a Human Factors consultant at SNC-Lavalin Rail \& Transit (formerly Interfleet), London, UK.

Open Access This article is distributed under the terms of the Creative Commons Attribution 4.0 International License (http:// creativecommons.org/licenses/by/4.0/), which permits unrestricted use, distribution, and reproduction in any medium, provided you give appropriate credit to the original author(s) and the source, provide a link to the Creative Commons license, and indicate if changes were made. 


\section{References}

1. Unhelkar VV, Perez J, Boerkoel JC, Bix J, Bartscher S, Shah JA (2014) Towards control and sensing for an autonomous mobile robotic assistant navigating assembly lines. International Conference on Robotics and Automation (ICRA)

2. Bostelman R, Shackleford W (2010) Improved performance of an automated guided vehicle by using a smart diagnostics tool. International Conference on Industrial Technology (ICIT), Vi a del Mar

3. Guizzo E (2008) Three engineers, hundreds of robots, one warehouse. IEEE Spectr 45(7):26-34

4. Tang G, Charalambous G, Webb P and Fletcher SR (2014) Users' understanding on industrial robot gesture motions and effects on trust. In: Contemporary Ergonomics and Human Factors 2014: Proceedings of the International Conference on Ergonomics \& Human Factors 2014. 7-10: (p. 116). CRC Press, Southampton

5. International Organisation for Standardisation (2011) Robots and robotic devices - safety requirements for industrial robots, part 1: robots. International Standards Organisation, Geneva

6. Chung CA (1996) Human issues influencing the successful implementation of advanced manufacturing technology. J Eng Technol Manag 13(3):283-299

7. Ghani KA, Jayabalan V (2000) Advanced manufacturing technology and planned organisational change. J High Technol Managem Res 11(1):1-18

8. Waldeck NE (2000) Advanced manufacturing technologies and workforce development. Garland Press, New York

9. Lewis MW, Boyer KK (2002) Factors impacting AMT implementation: an integrative and controlled study. J Eng Technol Manag 19(2):111-130

10. Castrillón ID, Cantorna AIS (2005) The effect of the implementation of advanced manufacturing technologies on training in the manufacturing sector. J Eur Ind Train 29(4):268-280

11. Zammuto RF, O'Connor EJ (1992) Gaining advanced manufacturing technologies' benefits: the roles of organization design and culture. Acad Manag Rev 17(4):701-728

12. McDermott CM, Stock GN (1999) Organisational culture and advanced manufacturing technology implementation. J Oper Manag 17(5):521-533

13. Pun KF (2002) Development of an integrated TQM and performance measurement system for self-assessment: a method. Total Qual Manag 13(6):759-777

14. Wemmerlov U, Johnson DJ (2000) Empirical findings on manufacturing cell design. Int J of Prod Res 38(3):481-507

15. Udo GJ, Ehie IC (1996) Advanced manufacturing technologies. Determinants of implementation success. Int J Oper Prod Manag 16(12):6-26

16. Fraser K, Harris K, Luong L (2007) Improving the implementation effectiveness of cellular manufacturing: a comprehensive framework for practitioners. Int J Prod Res 45(24):5835-5856

17. Charalambous G, Fletcher RS, Webb P (2015) Identifying the key organisational human factors for introducing human-robot collaboration in industry: an exploratory study. Int J Adv Manuf Technol 81(9):2143-2155

18. Charalambous G (2015) The development of a human factors tool for the successful implementation of industrial human-robot collaboration. $\mathrm{PhD}$ Thesis. Cranfield University. Bedfordshire, UK
19. Mankins JC (2009) Technology readiness assessments: a retrospective. Acta Astronaut 65(9):1216-1223

20. Mankins JC (1995) Technology readiness levels. White Paper

21. Nakamura H, Kajikawa Y, Suzuki S (2013) Multi-level perspectives with technology readiness measures for aviation innovation. Sustain Sci 8(1):87-101

22. Klar D, Frishammar J, Roman V \& Hallberg D (2016) A technology readiness level scale for iron and steel industries. Ironmaking \& Steelmaking Vol 43, pp 1-6

23. Azizian N, Sarkani S \& Mazzuchi T (2009) A comprehensive review and analysis of maturity assessment approaches for improved decision support to achieve efficient defense acquisition. In Proceedings of the World Congress on Engineering and Computer Science Vol 2, pp 20-22

24. Morgan J (2008) Manufacturing Readiness Levels (MRLs) and Manufacturing Readiness Assessments (MRAs). Air Force Research Lab Wright-Patterson AFB, OH, Manufacturing Technology Division

25. Wanberg CR, Banas JT (2000) Predictors and outcomes of openness to changes in a reorganizing workplace. J Appl Psychol 85(1): $132-142$

26. Jimmieson NL, Peach M, White KM (2008) Utilising the theory of planned behavior to inform change management: an investigation of employee intentions to support organisational change. J Appl Behav Sci 44(2):237-262

27. Smelzer LR, Zener MF (1992) Development of a model for announcing major layoffs. International Journal of Group and Organisation Management 17(4):446-472

28. DiFonzo N, Bordia P (1998) A tale of two corporations: managing uncertainty during organisational change. Hum Resour Manag 37(3-4):295-303

29. Neubert MJ, Kacmar KM, Carlson DS, Chonko LB, Roberts JA (2008) Regulatory focus as a mediator of the influence of initiating structure and servant. J Appl Psychol 93(6):1220-1233

30. Kark R, Van Dijk D (2007) Motivation to lead, motivation to follow: the role of the self regulatory focus in leadership processes. Acad Manag Rev 32(2):500-528

31. Vollman $\mathrm{T}$ (1996) The transformation imperative: achieving market dominance through radical change. Harvard Business School Press, Boston

32. Somers TM \& Nelson K (2001) The impact of critical success factors across the stages of enterprise resource planning implementation. In Proceedings of the 34th Hawaii International Conference on Systems Sciences (HICSS-34), Maui

33. Boyer M, Sovilla L (2003) How to identify and remove the barriers for a successful lean implementation. Journal of Ship Production 19(2):116-120

34. Zammuto RF, O'Connor EJ (1992) Gaining advanced manufacturing technologies' benefits: the roles of organization design and culture. Acad Manag Rev 17(4):701-728

35. Wall TD, Cordery JL, Clegg CW (2002) Empowerment, performance, and operational uncertainty: a theoretical integration. Appl Psychol Int Rev 51(1):146-169

36. Quinn RE (1988) Beyond rational management: mastering the paradoxes and competing demands of high-performance. Jossey-Bass, San Francisco

37. McDermott CM, Stock GN (1999) Organisational culture and advanced manufacturing technology implementation. J Oper Manag 17(5):521-533 